\title{
PROF. DRA. MERCEDES TRAVERSA
}

\section{MERCEDES TRAVERSA MD PHD}

El 16 de marzo de 2016 falleció en Buenos Aires Mercedes Traversa, Médica de Planta de la División Diabetología del Hospital de Clínicas José de San Martín.

Considerando el aspecto profesional, era Doctora en Medicina, Profesora Adjunta de Medicina Interna de la Universidad de Buenos Aires (UBA). Fue Directora de la Escuela de Graduados de la Sociedad Argentina de Diabetes (SAD) y Directora del Postgrado en Diabetes para Médicos del Exterior de la SAD. Integró diferentes comisiones directivas y comités de trabajo de la SAD, se desempeñó como Secretaria de los programas de actualización a distancia PROAMI (Programa de Actualización en Medicina Interna) y PROTERAP (Programa de Actualización en Terapéutica), participó de múltiples publicaciones científicas y capítulos de libros, y fue coautora del libro "Temas de Terapéutica Clínica".

Pero los títulos académicos son simplemente una parte de un todo y no describen realmente a Mercedes como se merece; sería no reconocer en ella lo más importante: su esencia. Nos gustaría definirla como una persona amable, lo que dicho de esta forma parece un adjetivo de compromiso y poco valor, pero si analizamos el significado de la palabra amable, significa digno de ser amado, y eso era Mercedes, una persona digna de ser amada por sus valores, los que siempre llevó como guía en su vida. Era amiga de sus amigos, defensora de sus principios, los que no eran negociables, transparente en sus pensamientos, puesto que no tenía nada que ocultar, luchadora incansable para que aquellas personas que tenían necesidades pudieran resolver sus problemas o de no tener solución ser esa mano que se necesita para aferrarse y no caer.
Docente de alma, generosa con sus conocimientos, no se guardaba nada que pudiera compartir, además de compañera de sus pacientes en el transitar por sus enfermedades.

El juramento hipocrático podría haberse inspirado en ella por la forma en que desempeñó la profesión; respetó y reconoció a sus maestros, la salud del enfermo fue prioridad en su accionar, siendo el respeto a la vida humana parte de su esencia; consideraciones de religión, raza, nacionalidad, ideas políticas y clase social nunca fueron motivo para realizar diferencias en el trato de sus pacientes; divulgó sus conocimientos y su arte con la convicción de que éstos no le pertenecían sino que eran de todos.

Mercedes era la honestidad, el valor, la valentía, la convicción, la fuerza, la pasión por el trabajo, el amor por la docencia, la generosidad. Mercedes fue muchas cosas, pero para nosotros fue maestra de la diabetes, de la docencia, del criterio y de la vida.

Tuvimos la suerte de compartir con ella muchos años de trabajo y ver cómo generaciones de médicos que se formaron con ella y cientos de pacientes que le confiaron su salud reconocieron sus virtudes. La vida nos la prestó mucho menos de lo que hubiéramos querido, pero lo suficiente como para agradecer el regalo enorme que fue conocerla. Lo que nos dejó es inconmensurable. Se fue una mujer de tamaño pequeño pero de gran altura. Dejó un lugar difícil de llenar. Gracias por el camino compartido. 